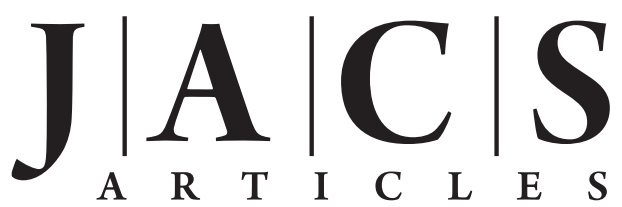

Published on Web 12/23/2009

\title{
Infrared Spectroscopy of Hydrated Bicarbonate Anion Clusters: $\mathrm{HCO}_{3}{ }^{-}\left(\mathrm{H}_{2} \mathrm{O}\right)_{1-10}$
}

\author{
Etienne Garand, ${ }^{\dagger}$ Torsten Wende, ${ }^{\ddagger}$ Daniel J. Goebbert, ${ }^{\ddagger, \perp}$ Risshu Bergmann, ${ }^{\ddagger}$ \\ Gerard Meijer, ${ }^{\ddagger}$ Daniel M. Neumark, ${ }^{*, t, \S}$ and Knut R. Asmis ${ }^{*, \neq}$ \\ Department of Chemistry, University of California, Berkeley, California 94720, \\ Fritz-Haber-Institut der Max-Planck-Gesellschaft, Faradayweg 4-6, 14195 Berlin, Germany, and \\ Chemical Science Division, Lawrence Berkeley National Laboratory, Berkeley, California 94720
}

Received November 3, 2009; E-mail: dneumark@ berkeley.edu; asmis@fhi-berlin.mpg.de

\begin{abstract}
Infrared multiple photon dissociation spectra are reported for $\mathrm{HCO}_{3}{ }^{-}\left(\mathrm{H}_{2} \mathrm{O}\right)_{1-10}$ clusters in the spectral range of $600-1800 \mathrm{~cm}^{-1}$. In addition, electronic structure calculations at the MP2/6-311+G(d,p) level have been performed on the $n=1-8$ clusters to identify the structure of the low-lying isomers and to assign the observed spectral features. General trends in the stepwise solvation motifs of the bicarbonate anion can be deduced from the overall agreement between the calculated and experimental spectra. The most important of these is the strong preference of the water molecules to bind to the negatively charged $\mathrm{CO}_{2}$ moiety of the $\mathrm{HCO}_{3}{ }^{-}$anion. However, a maximum of four water molecules interact directly with this site. The binding motif in the most stable isomer of the $n=4$ cluster, a four-membered ring with each water forming a single $\mathrm{H}$-bond with the $\mathrm{CO}_{2}$ moiety, is retained in all of the lowest-energy isomers of the larger clusters. Starting at $n=6$, additional solvent molecules are found to form a second hydration layer, resulting in a water-water network bound to the $\mathrm{CO}_{2}$ moiety of the bicarbonate anion. Binding of a water to the hydroxyl group of $\mathrm{HCO}_{3}{ }^{-}$is particularly disfavored and apparently does not occur in any of the clusters investigated here. Similarities and differences with the infrared spectrum of aqueous bicarbonate are discussed in light of these trends.
\end{abstract}

\section{Introduction}

The bicarbonate anion, $\mathrm{HCO}_{3}{ }^{-}$, is a ubiquitous species in aqueous chemistry. Because bicarbonate is a weak base, it plays a central role in the acid-base equilibrium formed when $\mathrm{CO}_{2}$ is dissolved in water:

$$
\mathrm{CO}_{2}+\mathrm{H}_{2} \mathrm{O} \leftrightarrow \mathrm{H}_{2} \mathrm{CO}_{3} \leftrightarrow \mathrm{HCO}_{3}^{-}+\mathrm{H}^{+} \leftrightarrow \mathrm{CO}_{3}^{2-}+2 \mathrm{H}^{+}
$$

This species is thus important in processes such as $\mathrm{pH}$ homeostasis in oceans, ${ }^{1}$ the formation of external skeletons by calcifying organisms, ${ }^{2}$ the transport of $\mathrm{CO}_{2}$ between the metabolizing tissues and the lungs, ${ }^{3}$ and the regulation of blood $\mathrm{pH}$. The nucleophilic attack of the hydroxide anion on $\mathrm{CO}_{2}$,

$$
\mathrm{OH}^{-}+\mathrm{CO}_{2} \rightarrow \mathrm{HCO}_{3}^{-}
$$

is a benchmark for the study of solvation effects on chemical reaction dynamics. ${ }^{4-9}$ While this reaction is predicted to proceed

\footnotetext{
$\pitchfork$ University of California.

$\doteqdot$ Fritz-Haber-Institut der Max-Planck-Gesellschaft.

$\S$ Lawrence Berkeley National Laboratory.

${ }^{\perp}$ Current address: Department of Chemistry, University of Arizona, Tucson, Arizona 85721-0041.

(1) Caldeira, K.; Wickett, M. E. Nature 2003, 425, 365.

(2) Orr, J. C.; et al. Nature 2005, 437, 681.

(3) Silverman, D. N.; Lindskog, S. Acc. Chem. Res. 1988, 21, 30.

(4) Peng, Z.; Merz, K. M. J. Am. Chem. Soc. 1993, 115, 9640.

(5) Davidson, M. M.; Hillier, I. H.; Hall, R. J.; Burton, N. A. Mol. Phys. 1994, 83, 327.
}

without a reaction barrier in the gas-phase, ${ }^{4,6,10}$ a substantial enthalpic barrier of $13.0 \pm 0.6 \mathrm{kcal} / \mathrm{mol}$ has been reported in aqueous solution. ${ }^{11,12}$ Solvent interactions with the reactants, products, and complex along the reaction coordinate are thus important in understanding the thermodynamics and kinetics of this reaction in the aqueous phase. In this paper, we report gas-phase infrared spectra of the $\mathrm{HCO}_{3}{ }^{-} \cdot\left(\mathrm{H}_{2} \mathrm{O}\right)_{1-10}$ clusters. These spectra, in combination with the accompanying electronic structure calculations, provide a detailed probe of bicarbonate anion microsolvation.

The gas-phase thermochemical properties of the bare bicarbonate anion have been studied via collision-induced dissociation and proton transfer reactions. ${ }^{13}$ The $\mathrm{HCO}_{3}{ }^{-}$anion has been studied by Raman and infrared spectroscopy in aqueous solution $^{14-18}$ and in the crystalline phase. ${ }^{17,19,20}$ Analysis of

(6) Nemukhin, A. V.; Topol, I. A.; Grigorenko, B. L.; Burt, S. K. J. Phys. Chem. B 2002, 106, 1734.

(7) Iida, K.; Yokogawa, D.; Sato, H.; Sakaki, S. Chem. Phys. Lett. 2007, $443,264$.

(8) Leung, K.; Nielsen, I. M. B.; Kurtz, I. J. Phys. Chem. B 2007, 111, 4453.

(9) Kumar, P. P.; Kalinichev, A. G.; Kirkpatrick, R. J. J. Phys. Chem. B 2009, 113, 794.

(10) Jonsson, B.; Karlstrom, G.; Wennerstrom, H. J. Am. Chem. Soc. 1978, $100,1658$.

(11) Pinsent, B. R. W.; Pearson, L.; Roughton, F. J. W. Trans. Faraday Soc. 1956, 52, 1512.

(12) Palmer, D. A.; Vaneldik, R. Chem. Rev. 1983, 83, 651.

(13) Squires, R. R. Int. J. Mass Spectrom. Ion Processes 1992, 117, 565.

(14) Davis, A. R.; Oliver, B. G. J. Solution Chem. 1972, 1, 329.

(15) Oliver, B. G.; Davis, A. R. Can. J. Chem. 1973, 51, 698.

(16) Dobson, K. D.; McQuillan, A. J. Langmuir 1997, 13, 3392. 
these spectra is complicated by possible counterion interactions and formation of bicarbonate dimers. Rudolph and co-workers have studied the infrared and Raman spectra of very dilute solutions of $\mathrm{KHCO}_{3}$ and $\mathrm{KDCO}_{3}$ and concluded that the hydrated $\mathrm{HCO}_{3}{ }^{-}$anion possess a $C_{1}$ symmetry, in contrast to the $C_{s}$ (planar) symmetry expected in the gas-phase. ${ }^{17,18}$ They also reported density functional theory (DFT) calculations on the $\mathrm{HCO}_{3}{ }^{-} \cdot\left(\mathrm{H}_{2} \mathrm{O}\right)_{1-3}$ clusters. ${ }^{17}$ While these bulk studies probe the structure of the $\mathrm{HCO}_{3}{ }^{-}$in solution, they do not provide detailed information on the microscopic structure of the solvation shells or the specific interactions between the solvent molecules and the anion. On the other hand, infrared spectroscopy of sizeselected ion clusters ${ }^{21-25}$ has emerged in recent years as a very powerful technique for probing microscopic ion hydration.

Here, we use vibrational action spectroscopy of gas-phase clusters to probe the microhydration of the $\mathrm{HCO}_{3}{ }^{-}$anion by studying the effect of stepwise hydration on its spectroscopy, structure, and energetics. We measure infrared multiple photon dissociation spectra of mass-selected $\mathrm{HCO}_{3}^{-} \cdot\left(\mathrm{H}_{2} \mathrm{O}\right)_{n}$ clusters at low temperature and in the absence of a counterion. The spectra are acquired in the spectral region spanning 550-1800 $\mathrm{cm}^{-1}$, which includes five of the characteristic vibrational modes of the anion as well as the libration and bending modes of the solvent molecules. The spectra are analyzed with the help of simulated linear absorption spectra from electronic structure calculations. This combination of experiment and theory has proved very useful in recent studies ${ }^{26,27}$ on the microhydration of the $\mathrm{SO}_{4}{ }^{2-}$ and $\mathrm{NO}_{3}{ }^{-}$anions.

\section{Experimental Details}

Infrared multiple photon photodissociation(IRMPD) experiments ${ }^{28,29}$ were carried out on a previously described ring electrode trap/timeof-flight mass spectrometer, ${ }^{30}$ which was temporarily installed at the "Free Electron Laser for Infrared eXperiments" (FELIX) user facility $^{31}$ in the FOM Institute Rijnhuizen (The Netherlands). $\mathrm{HCO}_{3}{ }^{-}\left(\mathrm{H}_{2} \mathrm{O}\right)_{n}$ ions were produced by electrospray of a $5 \mathrm{mM}$ solution of sodium bicarbonate $\left(\mathrm{NaHCO}_{3}\right)$ in a 1:1 mixture of water

(17) Rudolph, W. W.; Fischer, D.; Irmer, G. Appl. Spectrosc. 2006, 60, 130.

(18) Rudolph, W. W.; Irmer, G.; Konigsberger, E. Dalton Trans. 2008, 900.

(19) Bernitt, D. L.; Hartman, K. O.; Hisatsun, I. C. J. Chem. Phys. 1965 , 42, 3553.

(20) Nakamoto, K.; Sarma, Y. A.; Ogoshi, H. J. Chem. Phys. 1965, 43, 1177.

(21) Ebata, T.; Fujii, A.; Mikami, N. Int. Rev. Phys. Chem. 1998, 17, 331.

(22) Duncan, M. A. Int. J. Mass. Spectrom. 2000, 200, 545.

(23) Bieske, E. J.; Dopfer, O. Chem. Rev. 2000, 100, 3963.

(24) Robertson, W. H.; Johnson, M. A. Annu. Rev. Phys. Chem. 2003, 54, 173.

(25) Headrick, J. M.; Diken, E. G.; Walters, R. S.; Hammer, N. I.; Christie, R. A.; Cui, J.; Myshakin, E. M.; Duncan, M. A.; Johnson, M. A.; Jordan, K. D. Science 2005, 308, 1765.

(26) Goebbert, D. J.; Garand, E.; Wende, T.; Bergmann, R.; Meijer, G.; Asmis, K. R.; Neumark, D. M. J. Phys. Chem. A 2009, 113, 7584.

(27) Zhou, J.; Santambrogio, G.; Brümmer, M.; Moore, D. T.; Wöste, L.; Meijer, G.; Neumark, D. M.; Asmis, K. R. J. Chem. Phys. 2006, 125, 111102.

(28) Oomens, J.; Sartakov, B. G.; Meijer, G.; von Helden, G. Int. J. Mass. Spectrom. 2006, 254, 1.

(29) Asmis, K. R.; Fielicke, A.; von Helden, G.; Meijer, G. Vibrational Spectroscopy of Gas-Phase Clusters and Complexes. In Atomic Clusters: From Gas Phase to Deposited; Woodruff, D. P., Ed.; The Chemical Physics of Solid Surfaces, Vol. 12; Elsevier: Amsterdam, 2007; p 327.

(30) Goebbert, D.; Wende, T.; Bergmann, R.; Meijer, G.; Asmis, K. R. J. Phys. Chem. A 2009, 113, 5874.

(31) Oepts, D.; van der Meer, A. F. G.; van Amersfoort, P. W. Infrared Phys. Technol. 1995, 36, 297.

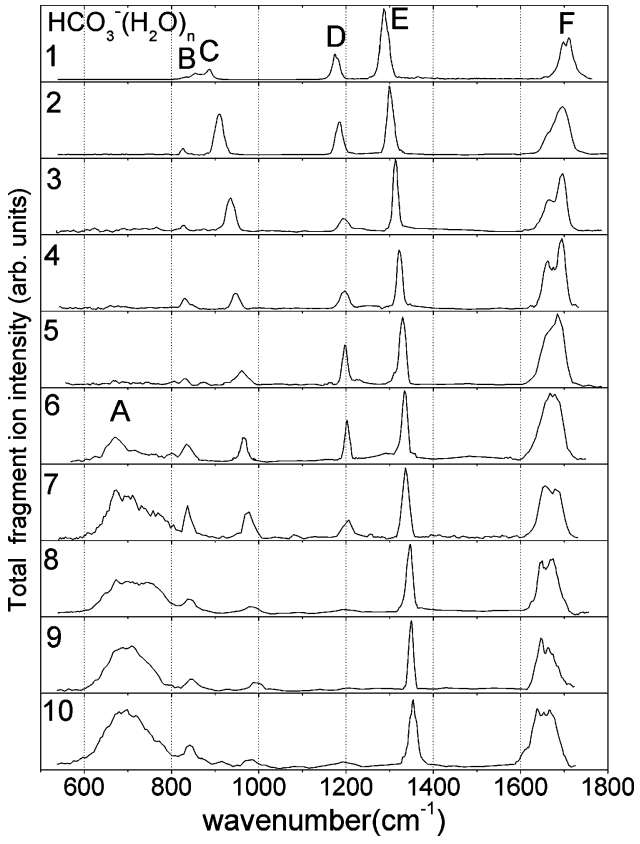

Figure 1. Experimental IRMPD spectra of $\mathrm{HCO}_{3}{ }^{-} \cdot\left(\mathrm{H}_{2} \mathrm{O}\right)_{n}$ ions with $n=$ $1-10$. The total fragment ion yield is plotted as a function of irradiation wavenumber $\left(\mathrm{cm}^{-1}\right)$.

and acetonitrile using a modified Waters $z$-spray source. The negative ions were transferred into a high vacuum system, sampled by a $3 \mathrm{~mm}$ diameter skimmer, and focused into a radio frequency (RF) linear ion guide. Ions of interest were then mass selected in a quadrupole mass trifilter, deflected by $90^{\circ}$ using an electrostatic quadrupole ion deflector, and focused into a linear, ring electrode $\mathrm{RF}$ ion trap. The ion trap was filled with He buffer gas and cooled to $12 \mathrm{~K}$ by means of a closed cycle He cryostat in order to cool the ions by collisions. The ions were accumulated and cooled in the trap for $195 \mathrm{~ms}$. They were then brought into the extraction region of a time-of-flight (TOF) mass spectrometer and irradiated with the pulsed radiation from FELIX prior to the application of high voltage pulses to the TOF plates. FELIX macropulses were used at a repetition rate of $5 \mathrm{~Hz}$, a pulse length of $5 \mu \mathrm{s}$, a laser wavelength bandwidth of $\sim 0.25 \%$ rms over the range from 550 to $1800 \mathrm{~cm}^{-1}$, and typical pulse energies of up to $50 \mathrm{~mJ}$.

\section{Results}

IRMPD spectra of $\mathrm{HCO}_{3}{ }^{-} \cdot\left(\mathrm{H}_{2} \mathrm{O}\right)_{n}$ clusters, with $n=1-10$ are shown in Figure 1. These spectra were generated by summing the yield of the various fragment ions as a function of the photodissociation laser wavelength and reflect the absorption spectrum of the parent ion. This signal was nearly background-free, in contrast to monitoring depletion of the parent ion signal. The only fragmentation pathways observed involved loss of one or more water molecules. The loss of more than one water molecule might have been due in part to fragment absorption as the different cluster sizes have similar infrared absorption bands. No fragmentation was observed for the bare $\mathrm{HCO}_{3}^{-}$anion.

The experimental IRMPD spectra comprise six bands labeled $\mathrm{A}-\mathrm{F}$ in Figure 1. Peak B, which appears as a small shoulder for the $n=1$ cluster, red-shifts from $860 \mathrm{~cm}^{-1}$ to $825 \mathrm{~cm}^{-1}$ upon addition of the second water. This peak subsequently blueshifts by only $16 \mathrm{~cm}^{-1}$ from $n=3-10$. Peak C blue-shifts from $887 \mathrm{~cm}^{-1}$ to $986 \mathrm{~cm}^{-1}$ as the number of waters increases. Peak D moves from $1177 \mathrm{~cm}^{-1}$ to $1205 \mathrm{~cm}^{-1}$ between $\mathrm{HCO}_{3}{ }^{-} \cdot\left(\mathrm{H}_{2} \mathrm{O}\right)_{1}$ and $\mathrm{HCO}_{3}{ }^{-} \cdot\left(\mathrm{H}_{2} \mathrm{O}\right)_{7}$ and is not observed for larger clusters. Peak 
Table 1. Peak Positions (in $\mathrm{cm}^{-1}$ ) in the $\mathrm{HCO}_{3}{ }^{-} \cdot\left(\mathrm{H}_{2} \mathrm{O}\right)_{1-10}$ Experimental IR Spectra ${ }^{a}$

\begin{tabular}{|c|c|c|c|c|c|c|}
\hline $\mathrm{HCO}_{3}^{-} \cdot\left(\mathrm{H}_{2} \mathrm{O}\right)_{n}$ & band $\mathrm{A}$ & $\begin{array}{l}\text { band B } \\
\left(\nu_{8}\right)\end{array}$ & $\begin{array}{c}\text { band C } \\
\left(\nu_{5}\right)\end{array}$ & $\begin{array}{l}\text { band D } \\
\left(v_{4}\right)\end{array}$ & $\begin{array}{l}\text { band } \mathrm{E} \\
\left(\nu_{3}\right)\end{array}$ & $\begin{array}{c}\text { band } \mathrm{F} \\
\left(v_{2}, \text { water bend }\right)\end{array}$ \\
\hline 1 & - & 859 & 887 & 1177 & 1288 & 1706 \\
\hline 2 & - & 826 & 909 & 1185 & 1301 & 1666,1697 \\
\hline 3 & - & 827 & 936 & 1196 & 1313 & 1666,1696 \\
\hline 4 & - & 832 & 948 & 1197 & 1323 & 1663,1694 \\
\hline 5 & - & 831 & 961 & 1198 & 1330 & 1663,1691 \\
\hline 6 & 675 & 837 & 966 & 1203 & 1334 & $\sim 1670$ \\
\hline 7 & $\sim 700$ & 837 & 976 & 1205 & 1337 & 1656,1686 \\
\hline 8 & $\sim 710$ & 841 & 983 & - & 1346 & 1646,1672 \\
\hline 9 & $\sim 700$ & 841 & 986 & - & 1349 & 1646,1665 \\
\hline 10 & $\sim 700$ & 841 & 986 & - & 1353 & $\sim 1653$ \\
\hline $\mathrm{HCO}_{3}{ }_{(\mathrm{aq})}{ }^{b}$ & 675 & 843 & 1014 & 1320 & 1364 & 1634 \\
\hline $\mathrm{HCO}_{3}{ }^{-}{ }_{(\mathrm{aq})}{ }^{c}$ & - & 844 & 1009 & - & 1359 & 1617 \\
\hline $\mathrm{H}_{2} \mathrm{O}_{(\mathrm{liq})}{ }^{d}$ & $\sim 690$ & & & & & $\sim 1640$ \\
\hline
\end{tabular}

${ }^{a}$ Band assignments are referenced to $\mathrm{HCO}_{3}{ }^{-}$vibrational modes in Figure 2. ${ }^{b}$ From ref $17 .{ }^{c}$ From ref $16 .{ }^{d}$ From ref 36.

$\mathrm{E}$, which is the most intense feature in most of the spectra, blueshifts from 1288 to $1353 \mathrm{~cm}^{-1}$ as the cluster size increases. Peak $\mathrm{F}$ is a broader feature whose individual components are partially resolved for only a few cluster sizes. In contrast to the other bands, it generally red-shifts as the number of water molecules increases. Finally, the peak labeled A is a broad, unresolved feature between 600 and $800 \mathrm{~cm}^{-1}$ that appears only in the spectra of $\mathrm{HCO}_{3}{ }^{-} \cdot\left(\mathrm{H}_{2} \mathrm{O}\right)_{6}$ and larger clusters. Experimental frequencies for $\mathrm{HCO}_{3}{ }^{-} \cdot\left(\mathrm{H}_{2} \mathrm{O}\right)_{1-10}$ are summarized in Table 1.

\section{Computational Details}

Electronic structure calculations were performed using the Gaussian 03 program $^{32}$ in order to assign the experimental spectra to particular solvation motifs of the $\mathrm{HCO}_{3}{ }^{-}$anion. Because of computational limitations, only the $n=1-8$ clusters were studied. Geometry optimizations were performed for a large number of initial structures of $\mathrm{HCO}_{3}{ }^{-} \cdot\left(\mathrm{H}_{2} \mathrm{O}\right)_{n}$ clusters using density functional theory, employing the B3LYP hybrid exchange-correlation functional ${ }^{33,34}$ and the $6-311+\mathrm{G}(\mathrm{d}, \mathrm{p})$ basis set. Vibrational analysis was performed on all the optimized geometries to ensure that the structures corresponded to local minima. The lowest-energy isomers were then reoptimized with the second-order Moller-Plesset (MP2) method using the same $6-311+\mathrm{G}(\mathrm{d}, \mathrm{p})$ basis set. The MP2 structures were found to be very similar to those obtained with DFT, but the energetic ordering of the various isomers often changed for the clusters with $n \geq 3$. In some instances, small differences in structures between isomers were observed, for instance an $\mathrm{H}$-atom pointing up or down, in which case the lowest-energy form was used, but for the purposes of our study these were not considered to be distinct isomers. Simulated infrared spectra were derived from the MP2/6-311+G(d,p) scaled harmonic frequencies (scaling factor: $0.970)^{35}$ and linear absorption intensities. For comparison with experimental results, stick spectra from the simulations were convoluted using a Gaussian line shape function with a $15 \mathrm{~cm}^{-1}$ full width at half-maximum (fwhm). All the energetics presented herein were derived from the MP2/6-311+G(d,p) values and include the scaled zero-point energy correction.

(32) Frisch, M. J.; et al. Gaussian 03, Revision C.02; Gaussian, Inc.: Wallingford CT, 2004.

(33) Lee, C.; Yang, W.; Parr, R. G. Phys. Rev. B 1988, 37, 785.

(34) Becke, A. D. J. Chem. Phys. 1993, 98, 5648.

(35) Scott, A. P.; Radom, L. J. Phys. Chem. 1996, 100, 16502.

(36) NIST Mass Spec Data Center; Stein, S. E., Director; Infrared Spectra. In NIST Chemistry WebBook, NIST Standard Reference Database Number 69; Linstrom, P. J., Mallard, W. G., Eds.; National Institute of Standards and Technology: Gaithersburg, MD, http://webbook.nist. gov, retrieved November 2, 2009).

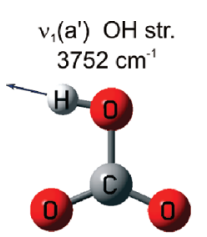

$v_{2}\left(a^{\prime}\right) \mathrm{CO}_{2}$ asym. str. $v_{3}\left(a^{\prime}\right) \mathrm{CO}_{2}$ sym. str.

$1734 \mathrm{~cm}^{-1} \quad 1259 \mathrm{~cm}^{-1}$

$v_{4}\left(a^{\prime}\right) \mathrm{COH}$ bend

$1171 \mathrm{~cm}^{-1}$
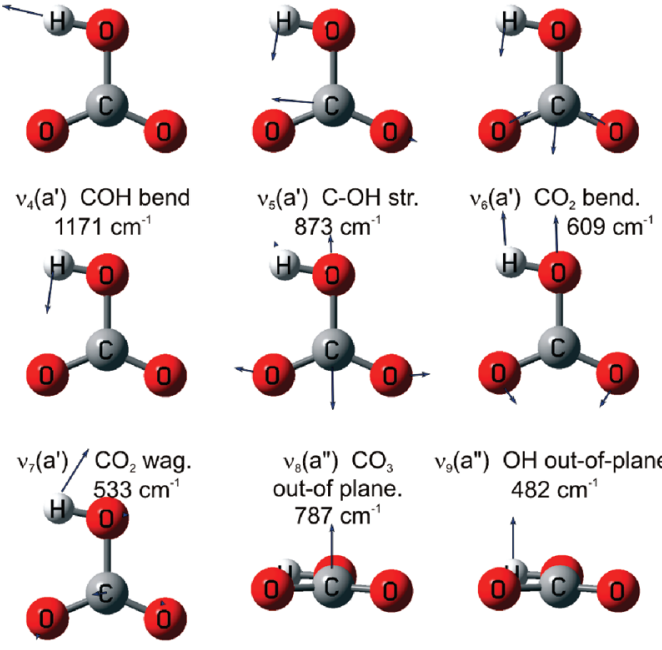

$\mathrm{v}_{8}(\mathrm{a}) \mathrm{CO}_{3}$

out-of plane.

$v_{9}(a ")$ OH out-of-plane.
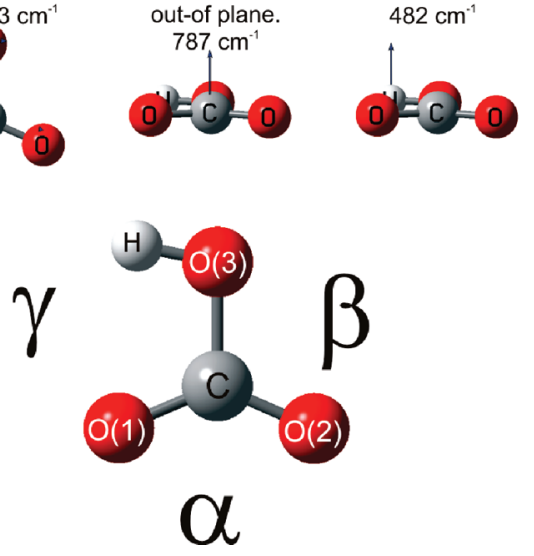

Figure 2. $\mathrm{HCO}_{3}{ }^{-}$normal modes and calculated gas-phase frequencies at the MP2/6-311+G(d,p) level as well as the atom and position labeling used in the Analysis and Discussion sections.

\section{Analysis}

The six bands observed in the IRPMD spectra can be readily assigned on the basis of previous infrared studies of $\mathrm{HCO}_{3}{ }^{-}$in bulk water ${ }^{17}$ and calculated vibrational frequencies of the bare and solvated anion. The normal modes of $\mathrm{HCO}_{3}{ }^{-}$are shown in Figure 2, along with their calculated and scaled gas-phase frequencies at the MP2/6-311+G(d,p) level of theory. The small peaks $\mathrm{B}$ and $\mathrm{C}$ are assigned to the $\mathrm{CO}_{3}$ out-of-plane mode $\left(v_{8}\right)$ and $\mathrm{C}-\mathrm{OH}$ stretching mode $\left(v_{5}\right)$, respectively. Peak $\mathrm{D}$ is assigned to the $\mathrm{COH}$ bending mode $\left(v_{4}\right)$, whereas the more intense peak $\mathrm{E}$ is assigned to the $\mathrm{CO}_{2}$ symmetric stretch $\left(v_{3}\right)$. Peak $\mathrm{F}$ is assigned to the $\mathrm{CO}_{2}$ asymmetric stretch $\left(v_{2}\right)$ of the anion core as well as the various water bending modes. ${ }^{36}$ These assignments are summarized in Table 1. Finally, peak $\mathrm{A}$ is located in the region where the $\mathrm{CO}_{2}$ bending mode $\left(v_{6}\right)$ is expected. However, this mode has very weak infrared absorption, ${ }^{17}$ and thus band $\mathrm{A}$ is instead assigned to the various water librational modes. ${ }^{36}$

The following sections summarize the theoretical and experimental results for each individual cluster. For each cluster up to $n=8$, the structures, energetics, and simulated linear absorption spectra of the three lowest-lying isomers are shown together with the corresponding experimental IRMPD spectra in Figures 3-10. The atom and position labeling used in this section and in section 6 is shown at the bottom of Figure 2.

5.1. $\mathbf{H C O}_{3}{ }^{-} \cdot\left(\mathbf{H}_{2} \mathbf{O}\right)$. In Figure 3 , the lowest-energy isomer, labeled 1-I, is a $C_{s}$ structure in which the water forms two $\mathrm{H}$-bonds with the negatively charged $\mathrm{CO}_{2}$ moiety of the $\mathrm{HCO}_{3}{ }^{-}$ anion. The 1-II isomer lies $3.4 \mathrm{~kJ} / \mathrm{mol}$ higher and consists of a doubly H-bonded water in which the hydroxyl group oxygen 


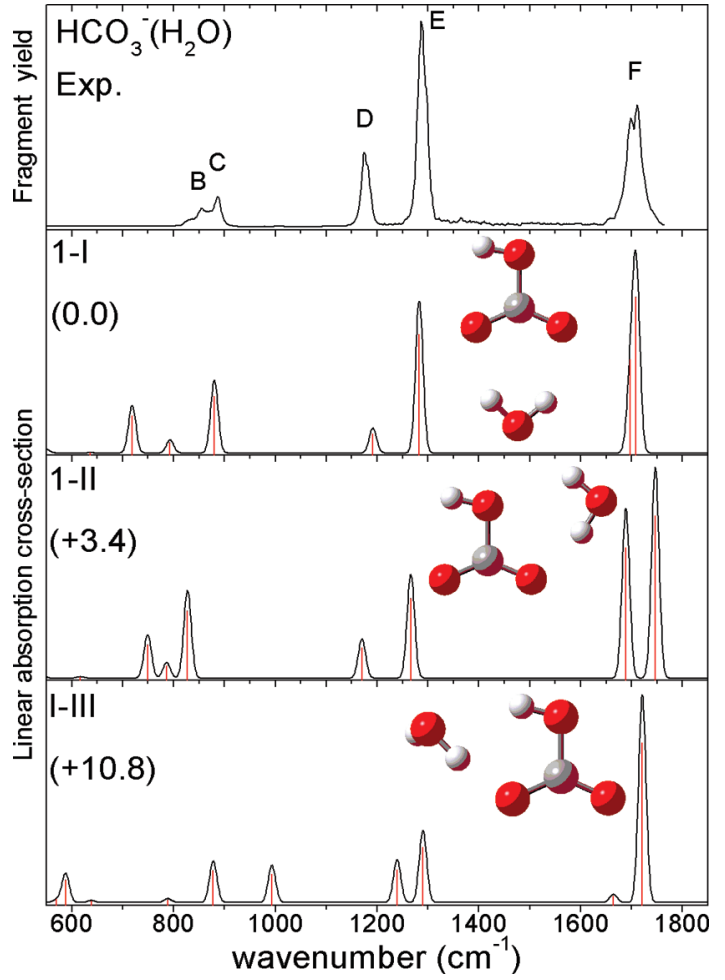

Figure 3. Experimental IRMPD spectrum of $\mathrm{HCO}_{3}{ }^{-} \cdot\left(\mathrm{H}_{2} \mathrm{O}\right)$ (top panel), with the simulated linear absorption spectra, structures, and relative energies $(\mathrm{kJ} / \mathrm{mol})$ of the three lowest-energy isomers.

of the $\mathrm{OH}$ and one oxygen of the $\mathrm{CO}_{2}$ act as acceptors. In this isomer, the water molecule is located slightly out of the $\mathrm{HCO}_{3}$ plane. In the third isomer, 1-III, the water forms one $\mathrm{H}$-bond with the $\mathrm{CO}_{2}$ moiety and acts as an acceptor for a second $\mathrm{H}$-bond with the $\mathrm{OH}$ group. This isomer lies $10.8 \mathrm{~kJ} / \mathrm{mol}$ above $1-\mathrm{I}$. No minima were found for isomers with a singly $\mathrm{H}$-bonded water at either the B3LYP/6-311+G(d,p) or MP2/6-311+G(d,p) level of theory.

The simulated infrared spectra of 1-I agrees best with experiment. This isomer yields calculated positions of peaks $\mathrm{C}-\mathrm{F}$ which are in excellent agreement with the experimental values. However, the simulated spectrum of 1-I includes a peak at $719 \mathrm{~cm}^{-1}$, corresponding to the water libration mode, that is not observed experimentally. The absence of features in the 550-800 $\mathrm{cm}^{-1}$ region of the IRMPD spectra of the small $\mathrm{HCO}_{3}{ }^{-} \cdot\left(\mathrm{H}_{2} \mathrm{O}\right)_{1-5}$ clusters is a general feature that will be discussed in section 6 . The presence of isomer 1-II can be eliminated on the basis of feature F. In the simulated spectra of 1-II, the water bending $\left(1692 \mathrm{~cm}^{-1}\right)$ and asymmetric $\mathrm{CO}_{2}$ stretching $\left(1746 \mathrm{~cm}^{-1}\right)$ modes form two distinct features, while only a single peak is observed in the IRMPD spectra. For isomer 1-III, peak D occurs at higher energy than in the experimental spectrum and an extra water vibrational feature at $993 \mathrm{~cm}^{-1}$ is predicted which is not seen experimentally. With reference to Figure 2, the position of the water in isomers 1-I to 1-III corresponds to the $\alpha, \beta$ and $\gamma$ sites, respectively, and this labeling scheme will be used to describe solvation motifs in the larger clusters.

5.2. $\mathrm{HCO}_{3}{ }^{-} \cdot\left(\mathrm{H}_{2} \mathrm{O}\right)_{2}$. Figure 4 shows that in the lowest energy isomer of the $n=2$ cluster, 2-I, the waters are at the $\alpha$ and $\beta$ sites, and each forms two $\mathrm{H}$-bonds with the $\mathrm{HCO}_{3}{ }^{-}$anion. The 2-II isomer lies higher in energy by $4.4 \mathrm{~kJ} / \mathrm{mol}$ and consists of two waters in the $\alpha$ position connected by a water-water $\mathrm{H}$-bond, each of which is singly bonded to the $\mathrm{HCO}_{3}{ }^{-}$. The

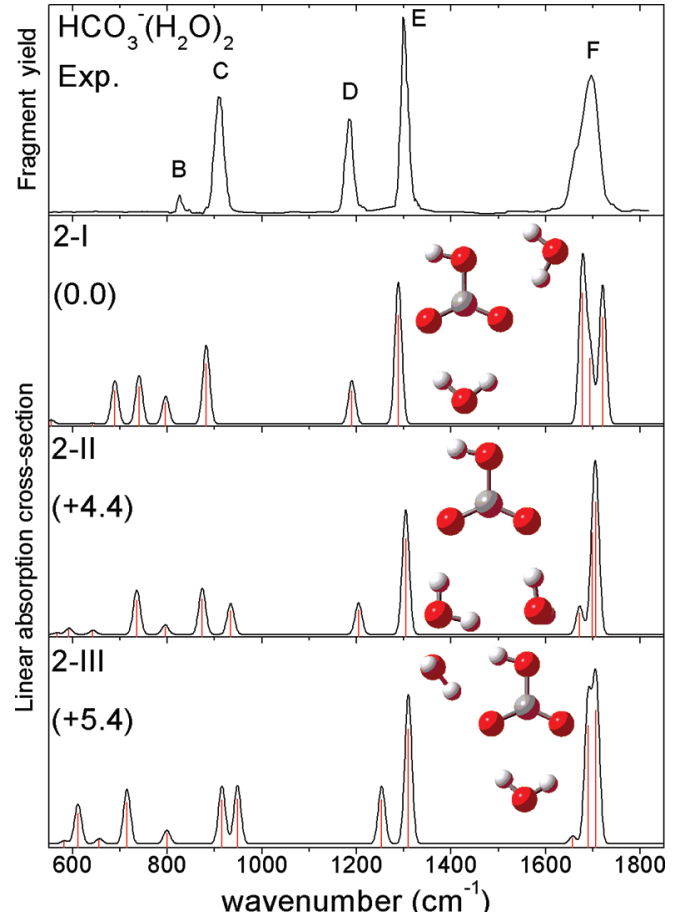

Figure 4. Experimental IRMPD spectrum of $\mathrm{HCO}_{3}{ }^{-} \cdot\left(\mathrm{H}_{2} \mathrm{O}\right)_{2}$ (top panel), with the simulated linear absorption spectra, structures, and relative energies $(\mathrm{kJ} / \mathrm{mol})$ of the three lowest-energy isomers.

2-III isomer, which lies $5.4 \mathrm{~kJ} / \mathrm{mol}$ above 2-I, consists of a doubly H-bonded water in the $\alpha$ position and another in the $\gamma$ position. No minima were found for isomers with two doubly H-bonded waters at the same site.

The simulated spectrum of 2-I agrees best with experiment. The main discrepancy is the splitting of peak $\mathrm{F}$ which is smaller and not resolved in the experimental spectra. In the simulated spectra of 2-II and 2-III, peak C is split into two distinct features, that are not observed experimentally. These two modes can be described as the linear combination of the $\mathrm{C}-\mathrm{OH}$ stretching motion and the libration of the singly $\mathrm{H}$-bonded water. Also, in 2-III (as in 1-III), the water at the $\gamma$ position induces a blueshift of peak D with respect to the experimental frequency.

5.3. $\mathbf{H C O}_{3}{ }^{-} \cdot\left(\mathbf{H}_{2} \mathbf{O}\right)_{3}$. In the lowest-energy isomer for the $n$ $=3$ cluster, 3 -I, the three waters are in the $\alpha$ position, as shown in Figure 5. Each forms one $\mathrm{H}$-bond with the $\mathrm{HCO}_{3}{ }^{-}$anion and another with an adjacent water, resulting in a threemembered water ring. The second isomer, 3-II, lies only 0.8 $\mathrm{kJ} / \mathrm{mol}$ above $3-\mathrm{I}$ and has one water molecule at each of the three sites. The 3-III isomer has two waters in the $\alpha$ position and one in the $\beta$ position. Note that isomer 3-II was found to be the global minimum at the B3LYP level, in accordance with the previous study of Rudolph et al. ${ }^{17}$ Once again, the simulated spectrum of the lowest-energy isomer offers the best agreement with the experiment. The simulated spectra of 3-II and 3-III exhibit a splitting of peak $\mathrm{C}$ that is not observed experimentally. Just as in isomers 2-II and 2-III, this splitting arises from two linear combinations of the $\mathrm{C}-\mathrm{OH}$ stretch and libration of the singly $\mathrm{H}$-bonded water. However, since the intensities of the libration bands are uncertain (see section 6), the presence of isomer 3-III cannot be ruled out. In 3-II, the calculated position of peak D at $1277 \mathrm{~cm}^{-1}$ is noticeably higher than the experimental frequency, $1196 \mathrm{~cm}^{-1}$. It thus appears that isomer 3-II does not contribute to the experimental spectrum. 


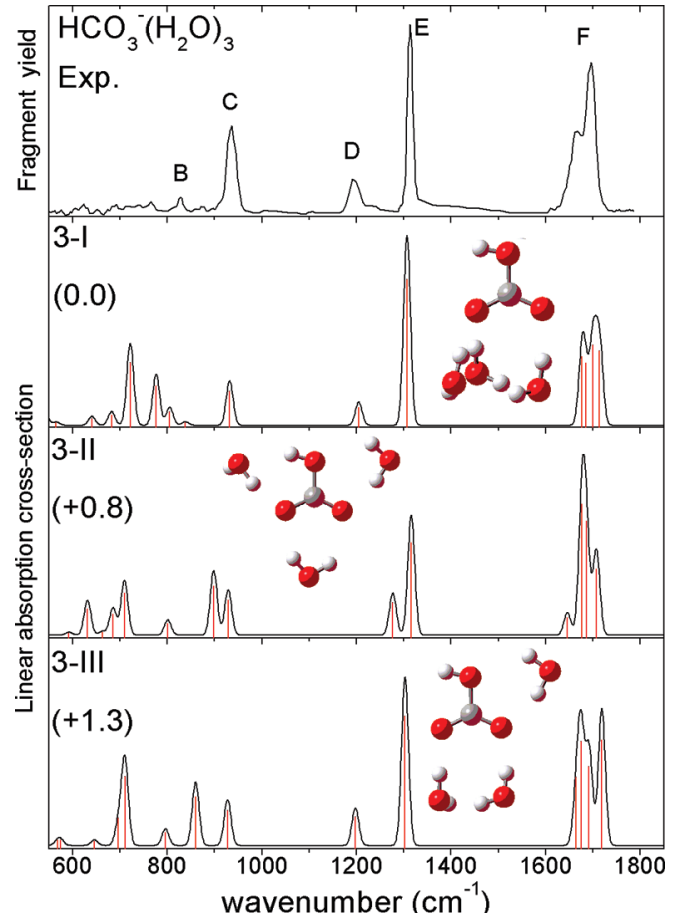

Figure 5. Experimental IRMPD spectrum of $\mathrm{HCO}_{3}{ }^{-} \cdot\left(\mathrm{H}_{2} \mathrm{O}\right)_{3}$ (top panel), with the simulated linear absorption spectra, structures, and relative energies $(\mathrm{kJ} / \mathrm{mol})$ of the three lowest-energy isomers.

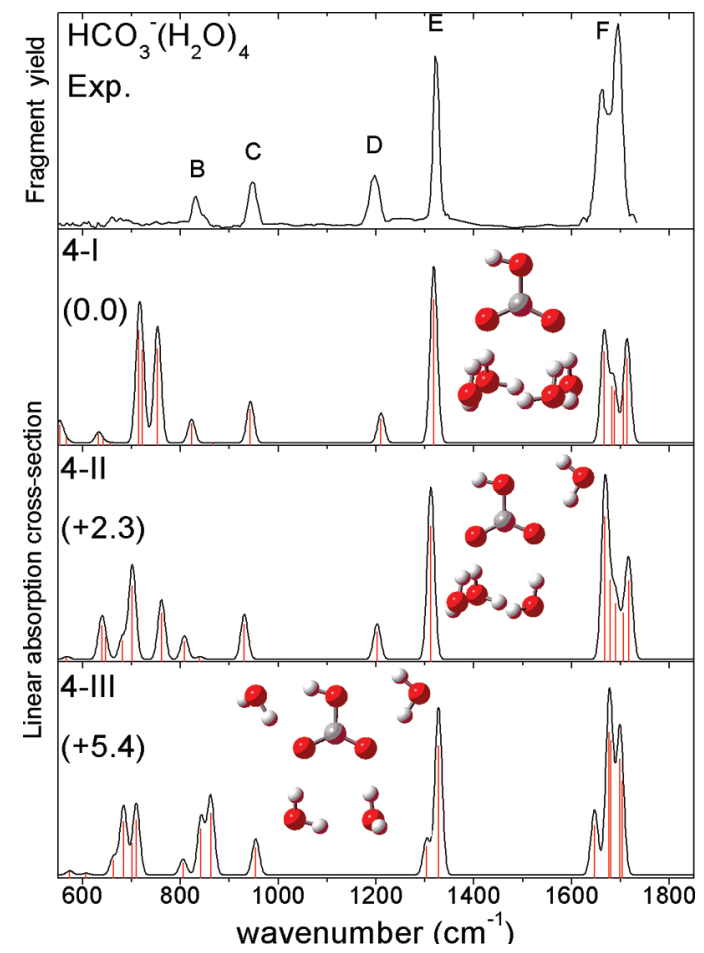

Figure 6. Experimental IRMPD spectrum of $\mathrm{HCO}_{3}{ }^{-} \cdot\left(\mathrm{H}_{2} \mathrm{O}\right)_{4}$ (top panel), with the simulated linear absorption spectra, structures, and relative energies $(\mathrm{kJ} / \mathrm{mol})$ of the three lowest-energy isomers.

5.4. $\mathrm{HCO}_{3}{ }^{-} \cdot\left(\mathbf{H}_{2} \mathbf{O}\right)_{4}$. Figure 6 shows results for the $n=4$ cluster. In the lowest-energy isomer, 4-I, all four waters are at the $\alpha$ site. Each forms one $\mathrm{H}$-bond with the $\mathrm{HCO}_{3}{ }^{-}$anion and another with an adjacent water, resulting in a four-membered ring. Isomer 4-II, lying $2.3 \mathrm{~kJ} / \mathrm{mol}$ above $4-\mathrm{I}$, has a threemembered ring in the $\alpha$ position, similar to $3-\mathrm{I}$, and the fourth water in the $\beta$ position. Isomer 4-III has two singly $\mathrm{H}$-bonded

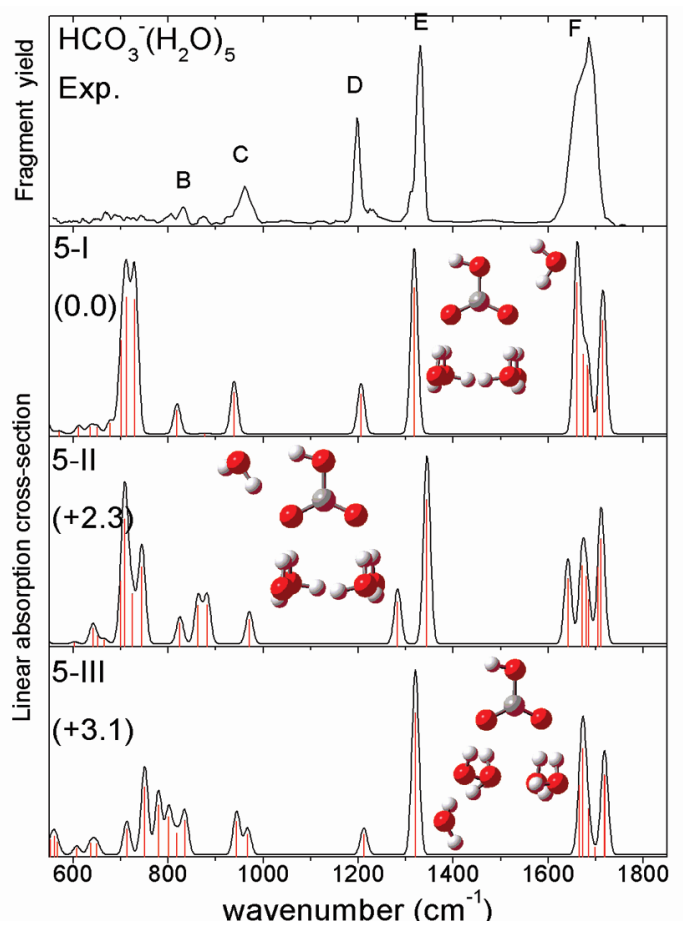

Figure 7. Experimental IRMPD spectrum of $\mathrm{HCO}_{3}{ }^{-} \cdot\left(\mathrm{H}_{2} \mathrm{O}\right)_{5}$ (top panel), with the simulated linear absorption spectra, structures, and relative energies $(\mathrm{kJ} / \mathrm{mol})$ of the three lowest-energy isomers.

waters in the $\alpha$ position, while the two remaining waters are at the $\beta$ and $\gamma$ sites. This isomer lies $5.4 \mathrm{~kJ} / \mathrm{mol}$ above $4-\mathrm{I}$.

The simulated spectra of 4-I and 4-II are very similar and in good agreement with experiment. The position and intensity of peak $\mathrm{F}$ is in slightly better agreement with the simulated spectrum of 4-I but the presence of 4-II cannot be ruled out. For isomer 4-III, the calculated position of peak $\mathrm{D}$ is blue-shifted with respected to the experimental value to such an extent that it appears as a shoulder on peak $\mathrm{E}$ in the simulation. Isomer 4-III was found to be the minimum energy structure at the B3LYP level which is again not consistent with the experimental observations.

5.5. $\mathrm{HCO}_{3}{ }^{-} \cdot\left(\mathrm{H}_{2} \mathrm{O}\right)_{5}$. For the $n=5$ cluster, shown in Figure 7 , the three lowest-energy structures each have four waters in the $\alpha$ position forming a single $\mathrm{H}$-bond with the $\mathrm{HCO}_{3}{ }^{-}$, similar to the ring arrangement in 4-I. In the lowest-energy isomer, labeled 5-I, the fifth water molecule is in the $\beta$ position, while it is at the $\gamma$ site in the 5-II isomer. In the 5-III isomer, the fifth solvent molecule does not bind directly to the $\mathrm{HCO}_{3}{ }^{-}$anion but rather to two other water molecules, thus forming a fivemembered hydrogen-bonded network in the $\alpha$ position. Isomers 5-II and 5-III are 2.3 and $3.1 \mathrm{~kJ} / \mathrm{mol}$ above the 5 -I structure, respectively.

The simulated spectra of 5-I and 5-III are in reasonable agreement with the experiment, but both overestimate the splitting of peak F. The spectrum of 5-I reproduces the experimental spectrum better around peaks B and C. Isomer 5-II can be ruled out on the basis of the doublet between peaks $\mathrm{B}$ and $\mathrm{C}$, that is not observed experimentally, and the predicted position of peak D which is blue-shifted with respect to the experimental value.

5.6. $\mathrm{HCO}_{3}^{-} \cdot\left(\mathrm{H}_{2} \mathrm{O}\right)_{6-8}$. Experimental and simulated spectra from the three calculated lowest-lying isomers of $\mathrm{HCO}_{3}{ }^{-} \cdot\left(\mathrm{H}_{2} \mathrm{O}\right)_{6-8}$ are shown in Figures 8, 9, and 10. For each of these three clusters, the calculated lowest-energy structure 


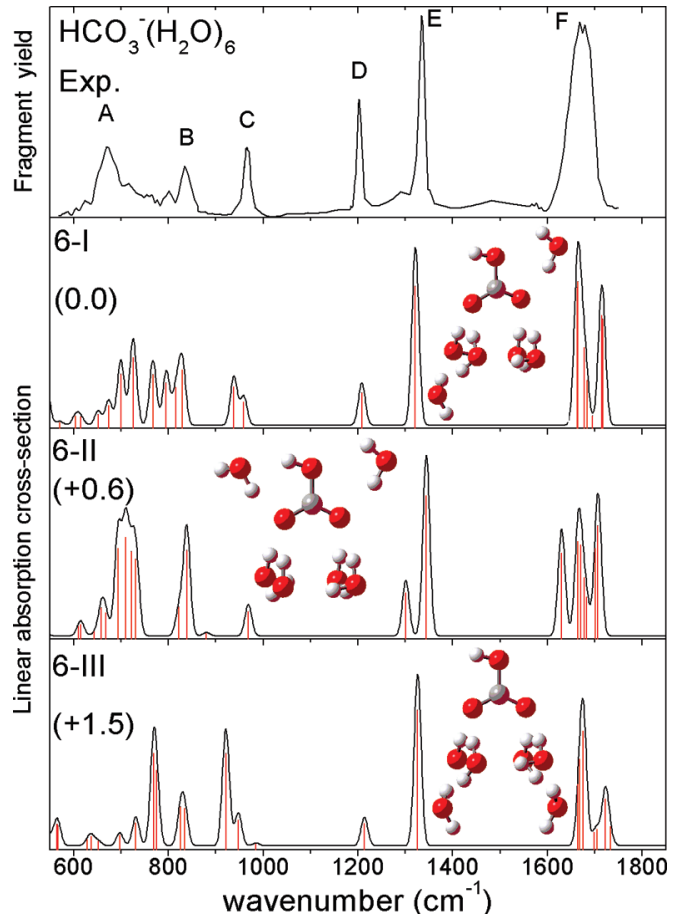

Figure 8. Experimental IRMPD spectrum of $\mathrm{HCO}_{3}{ }^{-} \cdot\left(\mathrm{H}_{2} \mathrm{O}\right)_{6}$ (top panel), with the simulated linear absorption spectra, structures, and relative energies $(\mathrm{kJ} / \mathrm{mol})$ of the three lowest-energy isomers.

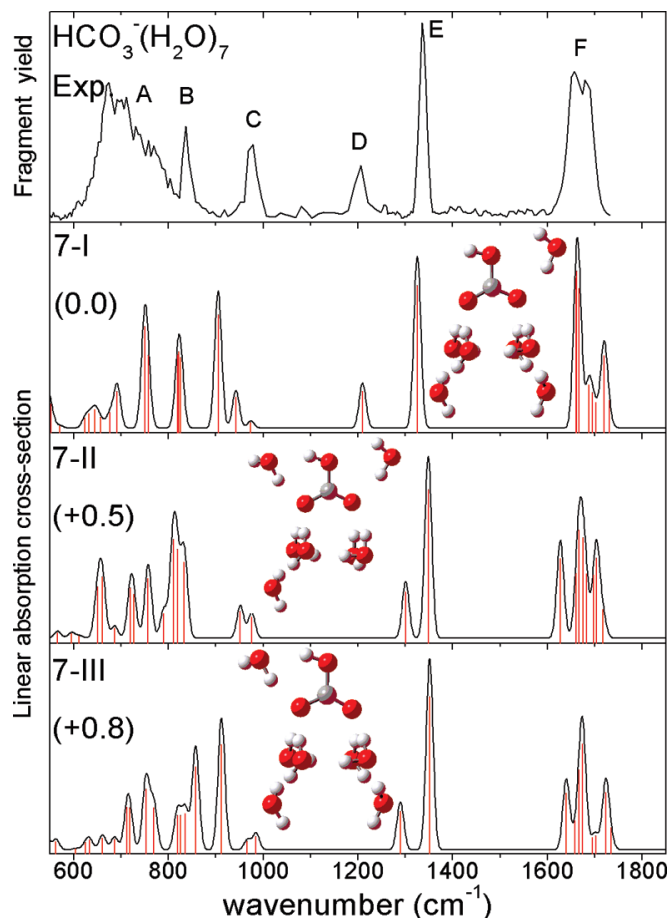

Figure 9. Experimental IRMPD spectrum of $\mathrm{HCO}_{3}{ }^{-} \cdot\left(\mathrm{H}_{2} \mathrm{O}\right)_{7}$ (top panel), with the simulated linear absorption spectra, structures, and relative energies $(\mathrm{kJ} / \mathrm{mol})$ of the three lowest-energy isomers.

is based on 5-I; the additional water molecules extend the water-water network at the $\alpha$ site and form a second solvation layer. Most of the other low-lying isomers in this range have one water binding in the $\gamma$ position. For the $n=6$ and $n=7$ clusters, we can rule out these isomers as the major contributors to the experimental spectra on the basis of the position of band $\mathrm{D}$, just as in the smaller clusters. However, for $n=6$, we observe

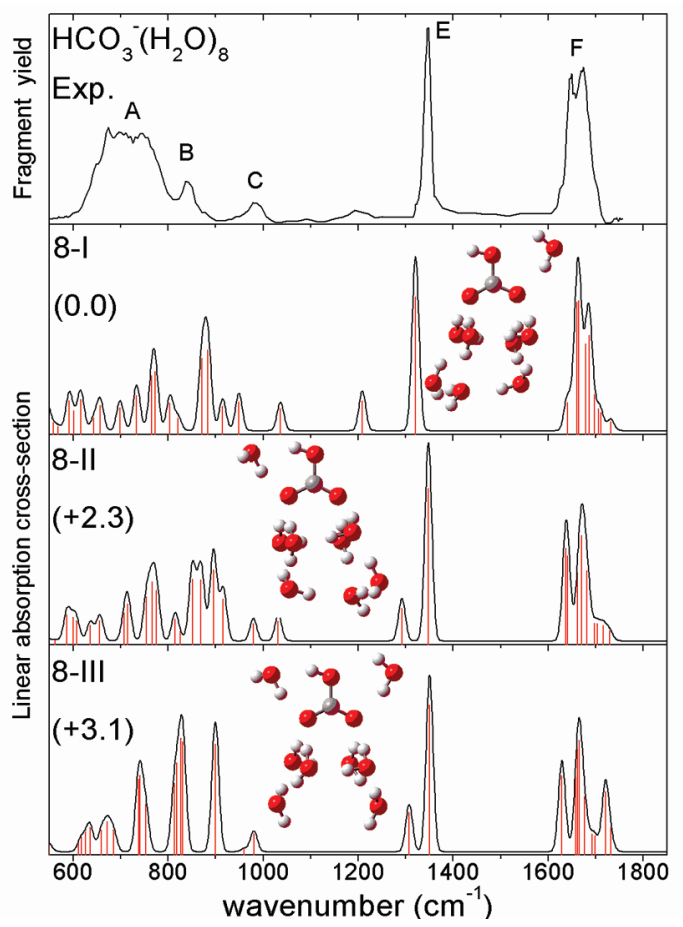

Figure 10. Experimental IRMPD spectrum of $\mathrm{HCO}_{3}{ }^{-} \cdot\left(\mathrm{H}_{2} \mathrm{O}\right)_{8}$ (top panel), with the simulated linear absorption spectra, structure, and relative energies $(\mathrm{kJ} / \mathrm{mol})$ of the three lowest-energy isomers.

a weak absorption at $\sim 1290 \mathrm{~cm}^{-1}$ which might indicate a small amount of 6-II. In the $n=8$ experimental spectrum, band D is not clearly observed, but there is a weak feature at $\sim 1200 \mathrm{~cm}^{-1}$ which corresponds to the calculated position of band $\mathrm{D}$ in isomer 8-I. The calculated shape of band F for 8-I is also in better agreement with the experimental spectrum than the other isomers. Thus, we conclude that 8-I is probably the main isomer present in the experiment.

\section{Discussion}

For some clusters, comparing the experimental and calculated spectra does not always identify a single isomer as being responsible for the spectrum. It is particularly difficult to distinguish between the isomers with water binding in the $\alpha$ or $\beta$ position, because they typically have very similar spectra in the energy range studied here. However, the overall good agreement between the calculated spectra and the experiment indicates that our binding motifs are reasonable. Clear trends emerge from the calculated stepwise solvation motifs presented here. The most striking of these is the strong preference of the water molecules for the $\alpha$ position. This trend is consistent with the classical picture of the bicarbonate anion in which the negative charge is shared by the $\mathrm{O}(1)$ and $\mathrm{O}(2)$ oxygen atoms. However, we find that four waters at most can directly interact with the $\mathrm{HCO}_{3}$ anion in the $\alpha$ position. The binding motif in isomer 4-I, in which each of the four waters in the $\alpha$ position forms a single $\mathrm{H}$-bond with the $\mathrm{CO}_{2}$ moiety, is retained in all the most stable isomers of the larger clusters.

Our calculations found a maximum of one water molecule bound to a bicarbonate site other than the $\alpha$ position in the most stable isomers. It is preferentially located at the $\beta$ site, forming H-bonds with both the $\mathrm{O}(2)$ and $\mathrm{O}(3)$ oxygen atoms of the bicarbonate anion. The isomers having water molecules in the $\gamma$ position were systematically found to be higher in energy. 
Moreover, these isomers always yielded a frequency for peak $\mathrm{D}$, the $v_{4} \mathrm{COH}$ bend, that was blue-shifted relative to the experimental spectra.

For clusters with $n>5$, five water molecules at most were found to interact directly with the bicarbonate anion. Starting at $n=6$, the additional solvent molecules formed a second hydration shell, extending the water-water network located at the $\alpha$ site. Finally, in all the isomers presented here, the water molecules were located within or close to the plane of the bicarbonate anion. Isomers with water located on top of the $\mathrm{HCO}_{3}{ }^{-}$core were significantly higher in energy. This result differs from the microsolvation motifs found for the similarly planar $\mathrm{NO}_{3}{ }^{-}$anion. For $\mathrm{NO}_{3}{ }^{-}\left(\mathrm{H}_{2} \mathrm{O}\right)_{n}$ cluster with $n=4-6$, the most stable isomers included a four-membered water ring located above the $\mathrm{NO}_{3}{ }^{-}$molecular plane. ${ }^{26}$

The monotonic frequency shifts observed in the IRMPD spectra as a function of cluster size are well-reproduced by the calculations. In order to understand these solvation-induced frequency shifts, we have to examine the effect of hydration on the $\mathrm{HCO}_{3}{ }^{-}$anion geometry. In the bare anion, the $\mathrm{C}-\mathrm{O}(1)$, $\mathrm{C}-\mathrm{O}(2)$, and $\mathrm{C}-\mathrm{O}(3)$ bond lengths are calculated to be 1.254 $\AA, 1.238 \AA$, and $1.452 \AA$, respectively, at the MP2/6-311+G(d,p) level. These bond lengths are consistent with the $\mathrm{C}-\mathrm{O}(3)$ having single bond character, while the $\mathrm{C}-\mathrm{O}(1)$ and $\mathrm{C}-\mathrm{O}(2)$ have $\sim 1.5$ bond character owing to sharing of the negative charge. The slightly longer $\mathrm{C}-\mathrm{O}(1)$ bond, with respect to $\mathrm{C}-\mathrm{O}(2)$, indicates that the interaction between the hydrogen and $\mathrm{O}(1)$ stabilizes the resonance structure in which the negative charge is on the $\mathrm{O}(1)$ atom. Upon the addition of a water in the $\alpha$ position, (isomer 1-I) the $\mathrm{C}-\mathrm{O}(3)$ bond length is reduced to $1.424 \AA$. On the other hand, the $\mathrm{C}-\mathrm{O}(1)$ and $\mathrm{C}-\mathrm{O}(2)$ bonds are slightly elongated to $1.259 \AA$ and $1.242 \AA$, respectively. In addition, the $\mathrm{O}(1) \mathrm{CO}(2)$ angle is slightly reduced, from $133.0^{\circ}$ to $131.2^{\circ}$. Thus, the interaction of water at the $\alpha$ position increases the strength of the $\mathrm{C}-\mathrm{O}(3)$ bond while weakening the $\mathrm{C}-\mathrm{O}(1)$ and $\mathrm{C}-\mathrm{O}(2)$ bonds. These trends continue as more water molecules are added at the $\alpha$ position. For example, in isomer 8-I, the $\mathrm{C}-\mathrm{O}(1), \mathrm{C}-\mathrm{O}(2)$, and $\mathrm{C}-\mathrm{O}(3)$ bond lengths are calculated to be $1.258 \AA, 1.251 \AA$, and $1.393 \AA$, respectively.

In the experimental spectra, bands $\mathrm{C}$ and $\mathrm{E}$ display the largest frequency shifts upon sequential addition of water molecules. They are blue-shifted by $99 \mathrm{~cm}^{-1}$ and $65 \mathrm{~cm}^{-1}$, respectively, as the cluster size increases from 1 to 10 water molecules. These two bands are assigned to the $v_{5}$ and $v_{3}$ modes, which primarily consist of $\mathrm{C}-\mathrm{O}(3)$ stretching motion. The large blue-shift observed for these bands is thus consistent with strengthening of the $\mathrm{C}-\mathrm{O}(3)$ bond induced by the water interactions in the $\alpha$ position. The frequency of the $v_{2}$ mode, which mainly involves $\mathrm{C}-\mathrm{O}(1)$ and $\mathrm{C}-\mathrm{O}(2)$ stretching motion, cannot be directly derived from our spectra because of the overlap with the bending mode of the water in band F. However, from the overall shifts of band F, we estimate that the frequency of this mode is redshifted by about $50 \mathrm{~cm}^{-1}$ as the cluster size increases from 1 to 10 water molecules. This trend is again consistent with the water interactions in the $\alpha$ position which elongate the $\mathrm{C}-\mathrm{O}(1)$ and $\mathrm{C}-\mathrm{O}(2)$ bonds. The frequency of the $v_{4}$ mode (band $\mathrm{D}$ ), the $\mathrm{CO}(3) \mathrm{H}$ bending motion, is blue-shifted by only $30 \mathrm{~cm}^{-1}$ with increasing cluster size. This is consistent with our calculations which show that no water molecule directly interacts with the $\mathrm{H}$ of the $\mathrm{HCO}_{3}{ }^{-}$core in the cluster size range studied here. The small blue-shift of band D might be from shortening of the $\mathrm{C}-\mathrm{O}(3)$ bond and increased charge on the $\mathrm{CO}_{2}$ moiety which would perturb the interaction between the $\mathrm{H}$ and $\mathrm{O}(1)$ atoms.

The only band which does not show a monotonic frequency shift upon solvation is peak $\mathrm{B}$, assigned to the $\mathrm{CO}_{3}$ out-of-plane mode. It red-shifts from $860 \mathrm{~cm}^{-1}$ to $825 \mathrm{~cm}^{-1}$ upon addition of the second water and subsequently blue-shifts by only 16 $\mathrm{cm}^{-1}$ from $n=3-10$. The calculation does not reproduce this non-monotonic behavior of peak B in the smaller clusters. It is possible that this discrepancy is due to anharmonic effects because in the solvated clusters, the $\mathrm{CO}_{3}$ out-of-plane mode of the bicarbonate anion also involves water libration motions. It is also possible that peak $\mathrm{B}$ in the $\mathrm{HCO}_{3}{ }^{-} \cdot\left(\mathrm{H}_{2} \mathrm{O}\right)$ experimental spectrum, where it appears as a small shoulder, does not correspond to the $\mathrm{CO}_{3}$ out-of-plane mode of isomer 1-I, but rather the $\mathrm{C}-\mathrm{OH}$ stretching mode (feature $\mathrm{C}$ ) of another isomer such as 1-II.

Some of the calculated absorption bands are not observed in the experimental spectra, most notably the absorption bands in the $600-800 \mathrm{~cm}^{-1}$ spectral region for clusters with $n<6$ (labeled as peak A in the larger clusters). These bands are from various water librational modes. Their absence in the experimental spectra is similar to what was observed for the $\mathrm{NO}_{3}{ }^{-}\left(\mathrm{H}_{2} \mathrm{O}\right)_{n}$ clusters ${ }^{26}$ and can originate from several effects. For example, the number of photons required to reach the dissociation continuum is 3 times larger at $600 \mathrm{~cm}^{-1}$ than at $1800 \mathrm{~cm}^{-1}$. This renders the low-frequency modes considerably more difficult to observe in our IRMPD spectra than those at higher frequencies. However, peaks B and C appear in our spectra with intensities close to their calculated linear absorptions, so frequency alone cannot explain the absence of peak A in small cluster sizes.

Structural changes that accompany IR multiphoton absorption offer a more likely origin for the absence of low-frequency librational bands. For example, in the 1-I isomer, the absorption of a few photons at the water librational mode frequency is not sufficient to break both $\mathrm{H}$-bonds, but can break a single $\mathrm{H}$-bond. However, the resulting singly bonded water cannot absorb any additional photons, because the absorption frequency of its librational mode has changed and is now out of resonance with the irradiation wavelength. This interpretation is supported by our experimental spectra in which the water libration band (band A) appears only for clusters with six or more water molecules, since $\mathrm{HCO}_{3}{ }^{-}\left(\mathrm{H}_{2} \mathrm{O}\right)_{6}$ is the smallest cluster in which the lowestlying isomer (isomer 6-I) contains a singly bonded water molecule. These clusters are thus more likely to dissociate rather than isomerize upon absorption of infrared photons. Moreover, the intensity of band A doubles in $\mathrm{HCO}_{3}{ }^{-}\left(\mathrm{H}_{2} \mathrm{O}\right)_{7}$, for which the lowest-energy isomer (7-I) contains two singly bonded water molecules.

In the cluster size range studied here, the frequencies of all the observed absorption bands monotonically shift toward their aqueous values as the number of water molecule is increased. With the exception of band $\mathrm{D}$, all the absorption bands are within $30 \mathrm{~cm}^{-1}$ of their position in aqueous solution by the $n$ $=10$ cluster. In the smaller clusters, band $\mathrm{D}$ is found to be more red-shifted than the other bands with respect to the aqueous frequencies. In the $n=7$ cluster, the largest cluster in which this band is clearly observed, band D is still $115 \mathrm{~cm}^{-1}$ below its aqueous frequency of $1320 \mathrm{~cm}^{-1}$. This difference can be easily understood from the calculated vibrational spectra of the various isomers. Our calculations found that cluster isomers with a water at the $\gamma$ site were systematically higher in energy. 
However, it can be seen from the calculated spectra of those isomers that a water molecule at the $\gamma$ position induces a $\sim 100$ $\mathrm{cm}^{-1}$ blue-shift of band D. In aqueous solution, at least one water molecule is certainly found in this position. It would be of interest to determine how large a cluster has to be before the lowest-energy structure has a water at the $\gamma$ site.

Finally, it is worthwhile to comment on the insights that the present study may yield on the structure of the fully hydrated bicarbonate anion. Careful examination of the polarization of the Raman modes in very dilute solutions of $\mathrm{KHCO}_{3}$ and $\mathrm{KDCO}_{3}$ led Rudolph and co-workers to conclude that the hydrated $\mathrm{HCO}_{3}{ }^{-}$anion has a $C_{1}$ symmetry in contrast to the $C_{s}$ symmetry expected in the gas-phase. ${ }^{17,18}$ In the clusters considered here, the calculated lowest-lying isomers all have a $\mathrm{HCO}_{3}{ }^{-}$anion with $C_{s}$ (planar) symmetry. However, the isomers having a water in the $\gamma$ position (such as 8-III) have a $\mathrm{HCO}_{3}{ }^{-}$ core with a $C_{1}$ symmetry, with a $\mathrm{O}(1) \mathrm{CO}(3) \mathrm{H}$ dihedral angle of about $2^{\circ}$. Thus, the $\mathrm{HCO}_{3}{ }^{-}$core may well adopt a geometry with $C_{1}$ symmetry in larger clusters and bulk water where the ion is fully solvated.

\section{Conclusion}

Infrared spectra are reported for the $\mathrm{HCO}_{3}{ }^{-}\left(\mathrm{H}_{2} \mathrm{O}\right)_{n}, n=1-10$ clusters in the $600-1800 \mathrm{~cm}^{-1}$ spectral range. Electronic structure calculations using DFT and MP2 have been performed on the $n=1-8$ species to determine the structure of the lowestlying isomers. Comparison of the experimental and calculated spectra does not always enable unambiguous identification of a single isomer for each cluster. Nonetheless, the overall good agreement between the calculated spectra and experiment allows us to determine general trends in the stepwise solvation motifs of the bicarbonate anion. The most important of these is the strong preference of water molecules to bind to the negatively charged $\mathrm{CO}_{2}$ moiety (the $\alpha$ site) of the $\mathrm{HCO}_{3}{ }^{-}$anion. However, a maximum of four waters can directly interact with the anion at this position. The binding motif in the most stable isomer of $n=4$, which consists of a four-membered ring with each water forming a single $\mathrm{H}$-bond with the $\mathrm{CO}_{2}$ moiety, is retained in all the most stable isomers of the larger clusters. Starting at $n=6$, the additional solvent molecules are found to form a second hydration shell, extending the water-water network located at the $\alpha$ site of the bicarbonate anion. We also find that binding at the hydroxyl group of $\mathrm{HCO}_{3}{ }^{-}$is disfavored for all clusters studied here; this result accounts for the largest discrepancy between the cluster spectra and the IR spectrum of aqueous bicarbonate.

Acknowledgment. We gratefully acknowledge the support of the Stichting voor Fundamenteel Onderzoek der Materie (FOM) in providing the required beam time on FELIX and highly appreciate the skillful assistance of the FELIX staff. EG and DMN were supported by the Air Force Office of Scientific Research under Grant No. F49620-03-1-0085. EG thanks the National Science and Engineering Research Council of Canada (NSERC) for a post graduate scholarship.

Supporting Information Available: Complete references 2 and 32. This material is available free of charge via the Internet at http://pubs.acs.org.

JA9093132 